\title{
KONFIGURASI DAN INSTALASI NETWORK MONITORING SYSTEM UNTUK APLIKASI PELAPORAN TAHUNAN PADA SERVER MILIK PT. XYZ
}

\author{
Shina Qolbunajati Atmaja \\ Program Studi Teknik Multimedia dan Jaringan \\ Jurusan Teknik Informatika dan Komputer \\ Politeknik Negeri Jakarta \\ shina.qolbunajatiatmaja.tik16@mhsw.pnj.ac.id
}

\begin{abstract}
Abstrak - Tujuan penelitian ini untuk mengimplementasikan network monitoring system untuk memantau pergerakan server pada server milik PT. XYZ. Software yang digunakan adalah Cacti, sebuah software opensource yang digunakan untuk network monitoring system. Cacti yang menyediakan fitur pemantauan kinerja jaringan yang meliputi trafik dan kepadatan serta sumber daya hardware seperti; sistem up/down, utilitas сри dan memory, kapasitas storage dan manajemen port. Sehingga memudahkan pegawai PT. XYZ untuk mengetahui kinerja dari server tersebut.
\end{abstract}

Kata Kunci: Cacti, kapasitas storage, Network Monitoring System, trafik jaringan

\section{Latar Belakang Kegiatan}

Salah satu penelitian selama melakukan PKL di PT. XYZ adalah Instalasi Dan Konfigurasi Network Monitoring System Server untuk Aplikasi Pelaporan Tahunan Milik PT.XYZ. Pada saat Penulis memulai kegiatan PKL di PT. XYZ, PT. XYZ belum memiliki Network Monitoring System untuk aplikasi pelaporan tahunan sehingga menyulitkan pegawai untuk mengetahui kinerja jaringan yang meliputi trafik dan kepadatan serta penggunaan sumber daya (resource) seperti; sistem up/down, utilitas сри dan memory, kapasitas storage dan manajemen port. Untuk itu Penulis ditugaskan menginstal dan mengkonfigurasi Network Monitoring System pada Server tersebut. Pada PKL ini, Penulis berkesempatan untuk mengimplementasi kemampuan IPTEK dalam bidang TIK yang diperoleh selama kuliah.

Oleh karena itu Penulis memilih judul

"Instalasi dan Konfigurasi Server untuk

Aplikasi PT.XYZ sebagai laporan

Praktek Kerja Lapangan Penulis.

\section{TINJAUAN PUSTAKA}

\subsection{Server}

Server adalah sebuah komputer yang bertugas untuk melayani permintaan dari komputer client di jaringan komputer. Server juga bertugas untuk mengatur lalu lintas data dalam sebuah jaringan dan menyediakan resource yang dapat digunakan oleh komputer lain yang terhubung di dalam jaringan. Dalam lingkup jaringan, Server dapat terdiri dari beberapa device seperti disk Server, 
file Server, database Server dan masih banyak lagi. Server akan bertugas menyediakan resource seperti sebuah aplikasi untuk dapat diakses oleh seluruh komputer client, sehingga pada saat komputer client me-request data maka komputer Server akan merespons permintaan tersebut dan kemudian akan mengatur pengiriman data pada client. Dengan demikian komputer Server dituntut harus mampu menyediakan resource yang memiliki kualitas yang jauh lebih tinggi dari komputer client seperti kualitas memory hardisk yang harus besar agar bisa menampung file sharing dalam kapasitas besar untuk seluruh komputer client.

\subsection{Network Monitoring System}

NMS merupakan perangkat lunak yang fungsi utamanya adalah memonitor dan mengelola perangkatperangkat jaringan dengan tujuan agar reliability dan availability terjaga dan dapat secara dini diketahui anomaly atau terputusnya jaringan tersebut (Syamsudin M 2013).

\subsubsection{Cacti}

Cacti adalah aplikasi monitoring open source dan berbasiskan web. Cacti pada umumnya dibuat untuk membuat data grafik seperti kinerja CPU dan bandwidth. Cacti khususnya digunakan pada antar muka switch dan router jaringan lewat SNMP untuk memonitor trafik jaringan. Cacti sendiri merupakan complete network graphing solution yang didesain dengan memanfaatkan RRD tool untuk data storage dan fungsi dari graphing tersebut (Syamsudin M 2013).. Di dalam Cacti terdapat beberapa fitur yang digunakan untuk proses monitoring dari Cacti tersebut. Fitur dari Cacti tersebut adalah:

a. Memory Usage berfungsi untuk mengetahui memory yang dipakai oleh Server, seberapa besar memory dari Server tersebut terpakai.Logged in user berfungsi untuk mengetahui dari user yang terhubung kepada Server tersebut.

b. Processor berfungsi untuk mengetahui kemampuan atau kinerja dari processor Server tersebut.

c. Partition berfungsi untuk mengetahui seberapa besar kapasitas storage yang terpakai oleh Server

\subsection{SNMP}

SNMP adalah sebuah protokol apikasi pada jaringan TCP/IP yang menangani manajemen jaringan. Protokol ini didesain sehingga pengguna dapat dengan mudah memantau kondisi jaringan computer . Pemantauan kondisi jaringan dapat dilakukan dengan cara pengumpulan nilai-nilai informasi dari kondisi jaringan secara jarak jauh atau menggunkan satu pusat pengamatan. 
SNMP menjadi protokol yang terus dikembangkan karena banyak perangkat jaringan yang mendukung dan tersedia layanan SNMP seperti router, switch, Server, workstation, dan printer. Protokol SNMP pada jaringan TCP/IP menggunakan transport UDP oleh karena itu dalam penggunaannya tidak akan membebani trafik jaringan. Pada sistem pemantauan jaringan dengan menggunakan layanan SNMP, terdapat tiga komponen dasar antara lain (Syamsudin M 2013):

1. Manajer SNMP adalah perangkat yang menjalankan dan dapat menangani tugas-tugas manajemen jaringan.

2. Agen SNMP adalah perangkat pada jaringan yang akan diamati dan dikelola. Setiap agen akan merespon dan menjawab permintaan manajer SNMP.

3. Management Information Base (MIB) pada SNMP dapat dikatakan sebagai tempat penyimpanan informasi yang dimiliki agen. MIB yang terdapat pada SNMP didefinisikan secara hirarki dan setiap bagian mempunyai identifikasi objek (OID).

\subsection{CentOS}

CentOS (Community Enterprise Operating System) merupakan Distro
Linux yang cocok digunakan dalam skala Enterprise selain itu juga gratis. CentOS di buat dari source code Red Hat Enterprise (RHEL) yang dikembangkan oleh sebuah komunitas yang disebut CentOS Project. Software ini dirilis dibawah General Public License (GPL) yang selanjutnya dikembangkan oleh sebuah komunitas yang disebut CentOS Project (Mauro, D., dan Schmidt, K. 2009).

Keuntungan linux CentOS adalah open source, kompatibilitas, user friendly. CentOS tersedia secara gratis, dukungan teknis utamanya disediakan terhadap para pengguna melalui milis, forum berbasis web, ataupun chat. Proyek CentOS tidak berafiliasi dengan Red Hat. Untuk penggalangan dana, CentOS berbasis donasi dari para pengguna serta sponsor dari perusahaan-perusahaan yang menggunakannya (Mauro, D., dan Schmidt, K.).

\subsection{Thold}

Thold adalah sebuah plugin yang terdapat di Cacti berfungsi untuk memeriksa data perangkat dalam grafik Cacti dan RRD Files yang menjadi dasar untuk mengirimkan peringatan ke admin melalui email, syslog dan SNMP Trap (https://docs.Cacti.net/plugin:thold).

\subsection{SendMail}

SendMail adalah sebuah Server email 
standar yang satu paket (built-in) dengan

sistem operasi Linux/Unix

(http://www.sendmail.org).

\subsection{Postfix}

Postfix adalah MTA (mail transfer agent) yang free dan open source. Postfix merupakan mail transfer agent default untuk sejumlah sistem operasi bertipe Unix. Postfix didistribusikan menggunakan Lisensi Umum IBM 1.0 yang merupakan lisensi perangkat lunak bebas tetapi tidak kompatibel dengan GPL (Frederick P. Brooks, Jr 2009). 


\section{HASIL PENILITAN}

\subsection{Uraian Praktek Kerja Lapangan}

Pada PKL ini ditugaskan untuk menginstall dan konfigurasi Network Monitoring System milik PT.XYZ. Dalam menyelesaikan tugas ini ada beberapa langkah yang harus di

\subsubsection{Mempresentasikan Network Monitoring System}

Dalam langkah ini membuat arsitektur sistem terdiri dari perangkat yang digunakan, langkah kerja sistem monitoring jaringan yang dibuat dan sistematika pelaporan notifikasi keadaan jaringan berupa Email yang dikirimkan kepada admin. Gambar 3.5 merupakan asitektur system network monitoring.

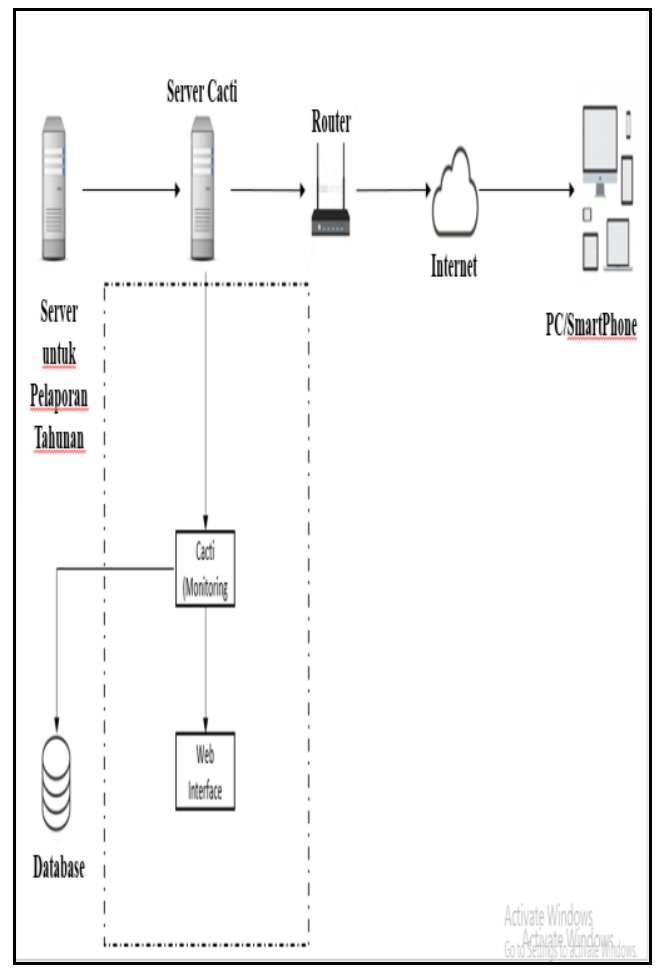

Gambar 3.5 Arsitektur sistem network selesaikan terlebih dahulu dapat. Langkah-langkah tersebut dapat dilihat pada gambar 3.4.

\begin{tabular}{|c|c|c|c|c|}
\hline Urian Praktik Keria & $\begin{array}{c}\text { List Kebutuhan } \\
\text { Napangan }\end{array}$ & $\begin{array}{c}\text { Instalasi dan } \\
\text { Network Monitoring } \\
\text { System }\end{array}$ & $\begin{array}{c}\text { Konfigurasi Cacti } \\
\text { pada Virtual Box }\end{array}$ & $\begin{array}{c}\text { Instalasi dan } \\
\text { Konfigursicacti } \\
\text { pada Sevver }\end{array}$ \\
\hline
\end{tabular}

Gambar 3.4 Tahapan pengerjaan praktek

kerja lapangan

monitoring

Berikut penjelasan arsitektur sistem pada gambar 3.5:

1. Server (yang telah diinstal Cacti) mendeteksi perubahan status pada komputer client.

2. Cacti memproses apakah perubahan status pada client perlu diberitahukan pada admin atau tidak.

3. Perubahan keadaan pada jaringan akan ditampilkan pada web interface Cacti.

4. Selain ditampilkan pada web, datadata yang dihasilkan juga akan tersimpan dalam database.

5. Notifikasi dikirim melalui email ke alamat admin melalui jaringan internet.

\subsubsection{List Kebutuhan Network Monitoring System}

List kebutuhan dilaksanakan setelah tahap perancangan hardware dan software yang akan digunakan. Secara garis besar langkah-langkah pelaksanaan implementasi yang akan dilakukan 
adalah sebagai berikut:

1. Melakukan instalasi CentOS 7.9 Server pada PC Server yang akan difungsikan sebagai Server Cacti.

2. Melakukan konfigurasi IP Address dan layanan SSH pada Server.

3. Melakukan instalasi LAMP Server (Linux, Apache, Mysql, PHP).

4. Melakukan instalasi dan konfigurasi repository epel.

5. Melakukan instalasi dan konfigurasi Cacti 1.2.8.

6. Melakukan instalasi dan konfigurasi Cacti Spine.

7. Melakukan instalasi dan konfigurasi Plugin Thold.

8. Melakukan instalasi dan konfigurasi Postfix.

9. Melakukan konfigurasi Email alert Cacti.

\subsubsection{Instalasi dan Konfigurasi Cacti pada Server dan Virtual Box}

Pada langkah ini PC Server maupun Virtual Box yang digunakan sebagai Server Cacti menggunakan sistem operasi CentOS 7. Gambar 3.6 merupakan flowchart instalasi dan konfigurasi Cacti pada Server dan Virtual Box.

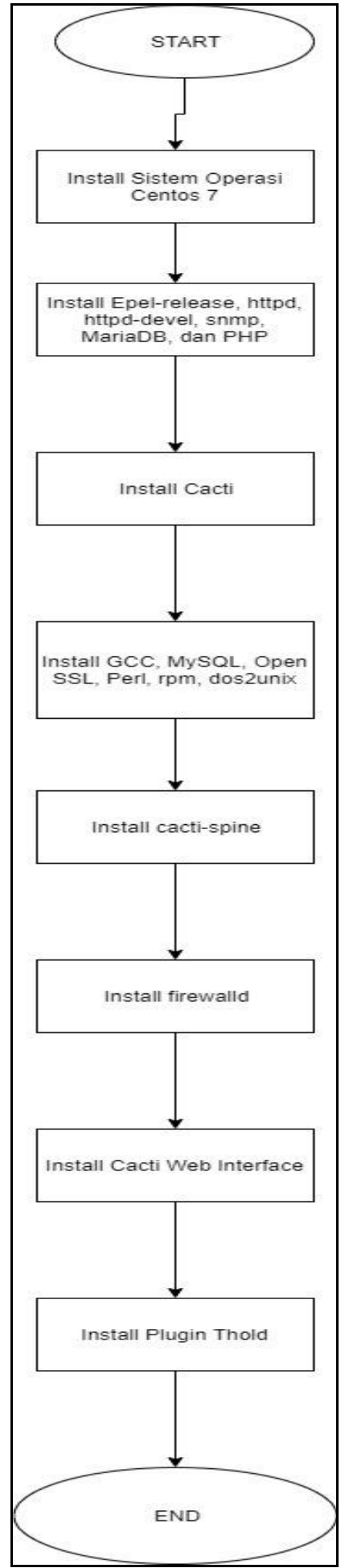

Gambar 3.6 Flowchart instalasi Cacti

\subsection{Pembahasan Hasil Praktek Kerja Lapangan}

Setelah berhasil melakukan installasi dan konfigurasi Cacti. Secara umum 
proses monitoring oleh Cacti dapat dilihat pada gambar 3.7.

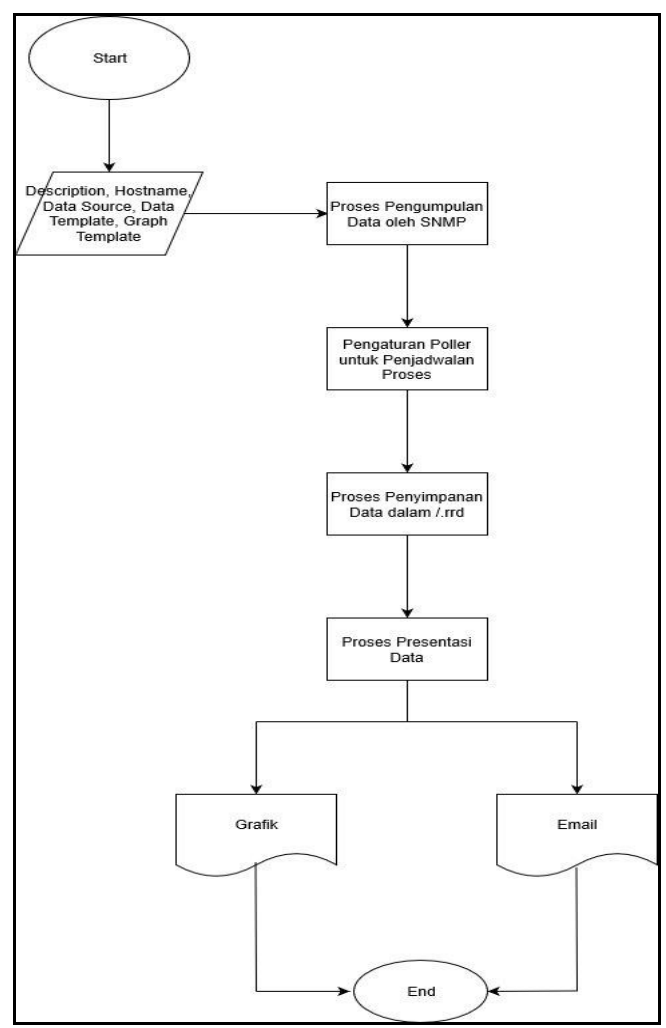

Gambar 3.7 Flowchart proses monitoring

Cacti

\subsubsection{Pengujian Proses Login Cacti}

Untuk masuk ke menu utama Cacti admin diharuskan memasukan username dan password pada halaman login. Berikut merupakan butir-butir pengujiannya. Pada table 3.1 pengujian proses login pada Cacti.

\subsection{Tabel pengujian proses login Cacti}

\begin{tabular}{|c|c|c|c|c|c|}
\hline Deskripsi & \begin{tabular}{|l|} 
Prosedur \\
Pengujian
\end{tabular} & Masukan & \begin{tabular}{|l|} 
Keluaran \\
yang \\
Diharapkan
\end{tabular} & \begin{tabular}{|l} 
Kriteria \\
Evaluasi \\
Hasil
\end{tabular} & $\begin{array}{l}\text { Hasil yang } \\
\text { Didapat }\end{array}$ \\
\hline \begin{tabular}{|l|} 
Pengujian \\
Proses Login \\
Cacti \\
\end{tabular} & 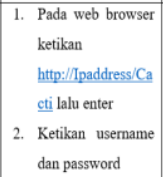 & \begin{tabular}{|l|} 
Username \\
dan Password
\end{tabular} & $\begin{array}{l}\text { Login Cacti } \\
\text { Berhasil. }\end{array}$ & $\begin{array}{l}\text { Login Cacti } \\
\text { Berhasil. }\end{array}$ & \begin{tabular}{|l} 
Login \\
CACTI \\
berhasil. \\
Dapat \\
mengakses \\
CACTI
\end{tabular} \\
\hline
\end{tabular}

Berikut hasil pengujian proses login pada Cacti. Pada gambar 3.26 tampilan masukan username dan password dan gambar 3.27 tampilan setelah berhasil masukan username dan password.

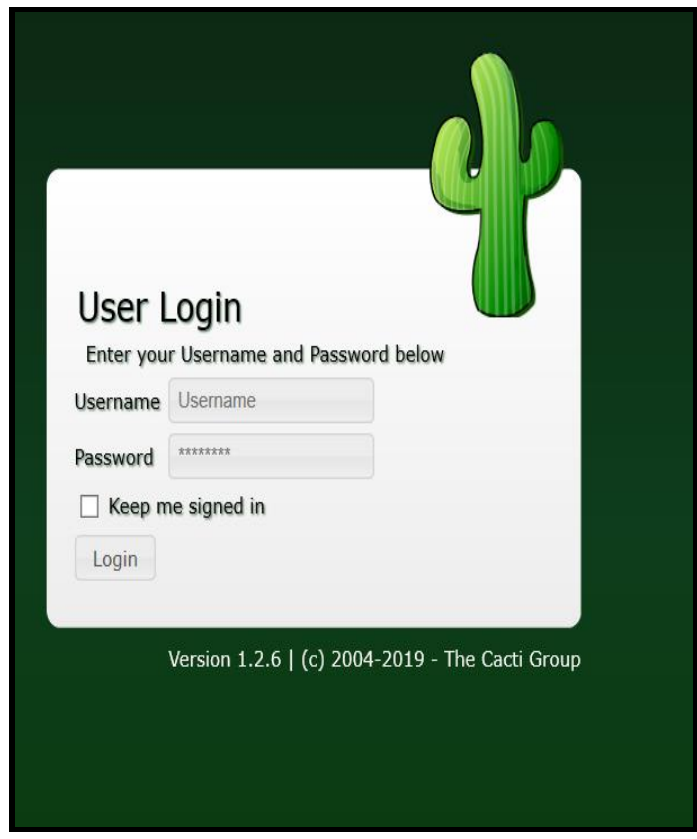

Gambar 3.26 Tampilan halaman login Cacti

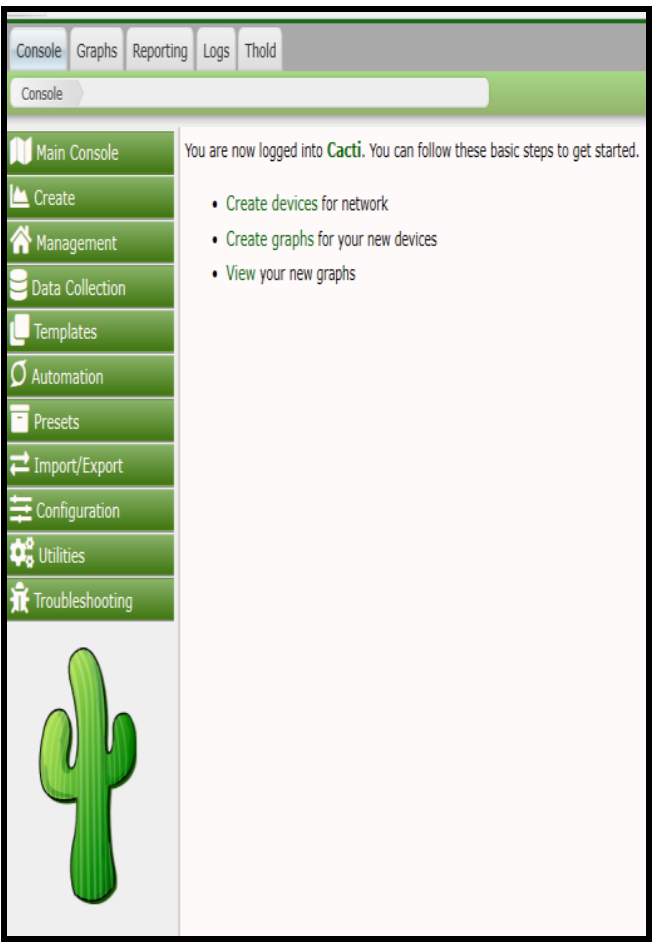


Gambar 3.27 Tampilan halaman utama Cacti

\subsubsection{Pengujian Pendaftaran Host}

Agar masalah suatu Host dapat didefenisikan dan dikirimkan, hal paling utama dilakukan adalah mendaftarkan Host tersebut dalam Cacti. Pada tabel 3.2 merupakan pengujian untuk pendaftaran Host pada Cacti.

\subsection{Tabel pengujian pendaftaran Host}

\begin{tabular}{|c|c|c|c|c|c|}
\hline Deskripsi & $\begin{array}{l}\text { Prosedur } \\
\text { Pengujian }\end{array}$ & Masukan & \begin{tabular}{|l|} 
Keluaran \\
yang \\
Diharapkan
\end{tabular} & \begin{tabular}{|l|} 
Kriteria \\
Evaluasi \\
Hasil
\end{tabular} & $\begin{array}{l}\text { Hasil yang } \\
\text { Didapat }\end{array}$ \\
\hline \begin{tabular}{|l|} 
Pengujian \\
Pendaftaran \\
Host pada \\
Thold
\end{tabular} & $\begin{array}{l}\text { 1. Pilihlah Host } \\
\text { dan grafik } \\
\text { 2. Masulkkan nilai } \\
\text { ambang batas }\end{array}$ & \begin{tabular}{|l|} 
Nilai \\
ambang \\
batas
\end{tabular} & $\begin{array}{l}\text { 1. Host dan } \\
\text { grafik } \\
\text { terdaftar } \\
\text { dalam thold } \\
\text { 2. Host dan } \\
\text { grafik } \\
\text { memiliki } \\
\text { nilai } \\
\text { ambang } \\
\text { batas }\end{array}$ & $\begin{array}{l}\text { Host dan } \\
\text { grafik } \\
\text { terdaftar } \\
\text { dalam thold } \\
\text { serta } \\
\text { memiliki } \\
\text { nilai ambang } \\
\text { batas }\end{array}$ & $\begin{array}{l}\text { Host dan } \\
\text { grafik } \\
\text { terdaftar } \\
\text { dalam thold } \\
\text { serta } \\
\text { memiliki } \\
\text { nilai ambang } \\
\text { batas }\end{array}$ \\
\hline
\end{tabular}

Untuk hasilnya dapat dilihat pada gambar 3.28.

\section{Devices}

Site Any * Data Collector Any " Template Any " Go Clear Export

Search Enter a search tem Q Status Any * Devices Default .

\begin{tabular}{|c|c|c|c|c|c|c|}
\hline \multicolumn{7}{|c|}{ All 3 Devices } \\
\hline Device Description & `Hostname & $f \mathbb{D} \uparrow$ & Graphs t & Data Sources & Status & In State f \\
\hline Coba & 10.10 .0 .153 & 3 & 24 & 18 & Down & 10:6h:Om \\
\hline Laptop & 1922.168 .43 .50 & 5 & 25 & 19 & Up & 3h:Om \\
\hline Local Linux Machine & localhost & 1 & 4 & 5 & Up & $N / A$ \\
\hline
\end{tabular}

4

Gambar 3.28 Hasil pengujian pendaftaran

Host

\subsubsection{Pengujian Pendaftaran Grafik}

Setelah Host terdaftar selanjutnya mendaftarkan grafik untuk Host. Pada tabel 3.3 merupakan pengujian untuk pendaftaran grafik pada Cacti.

\subsection{Tabel pengujian pendaftaran} grafik

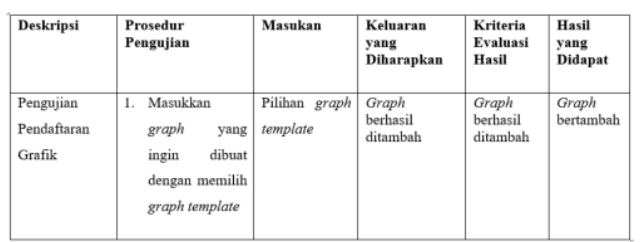

Hasil pengujian pendaftaran grafik dapat dilihat pada gambar 3.29.

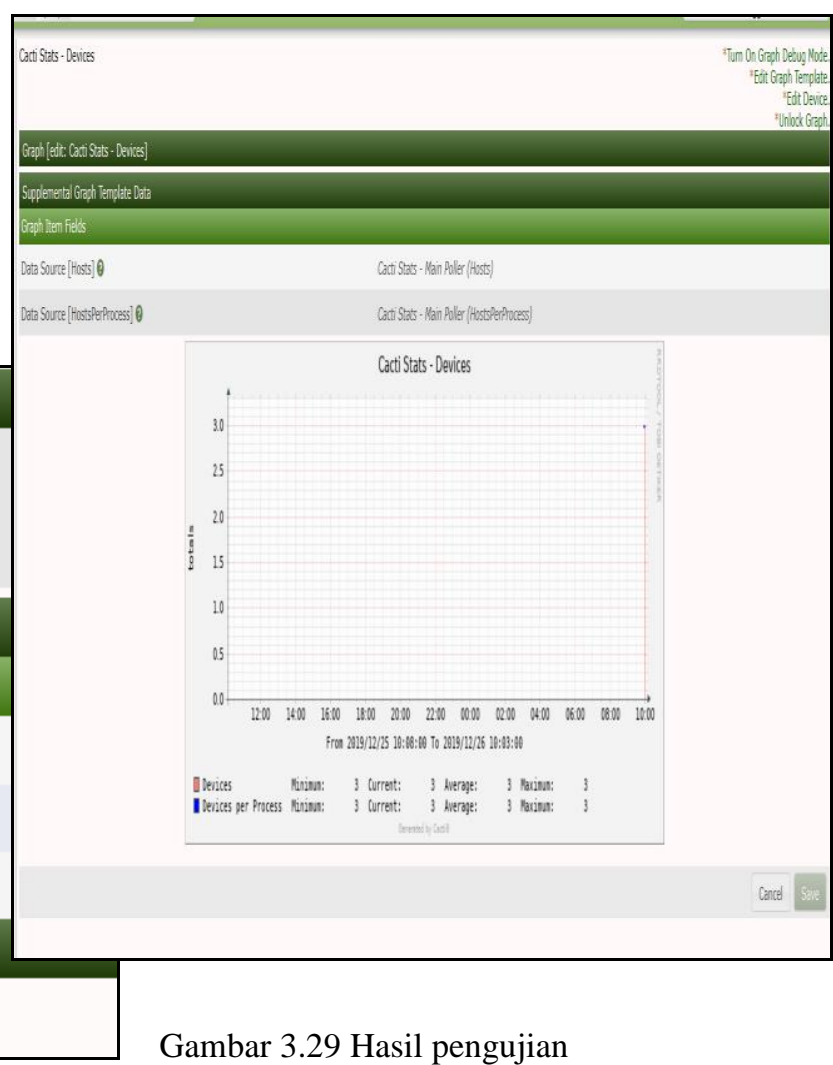

pendaftaran grafik 


\subsubsection{Pengujian Pendaftaran Host pada Thold}

Untuk Host yang telah didaftarkan dan telah ditentukan grafiknya, jika ingin memilki pemberitahuan kondisi Host haruslah didaftarkan pada Thold. Host dan graph yang telah didaftarkan serta nilai ambang batas yang telah diinputkan akan diproses oleh Thold sebagai parameter untuk mengetahui tingkat permasalahan Host. Pada tabel 3.4 merupakan pengujian untuk pendaftaran Host pada Thold.

\subsection{Tabel pengujian pendaftaran Host} pada Thold

\begin{tabular}{|c|c|c|c|c|c|}
\hline Deskripsi & $\begin{array}{l}\text { Prosedur } \\
\text { Pengujian }\end{array}$ & Masukan & \begin{tabular}{|l} 
Keluaran \\
yang \\
Diharapkan
\end{tabular} & \begin{tabular}{|l|} 
Kriteria \\
Evaluasi \\
Hasil \\
\end{tabular} & $\begin{array}{l}\text { Hasil } \\
\text { yang } \\
\text { Didapat }\end{array}$ \\
\hline $\begin{array}{l}\text { Pengujaan } \\
\text { Pendaftaran } \\
\text { Host pada Thold }\end{array}$ & $\begin{array}{l}\text { 1. Pilihlah Host dan } \\
\text { grafik } \\
\text { 2. Masulkkan nilai } \\
\text { ambang batas }\end{array}$ & $\begin{array}{l}\text { Nilai } \\
\text { ambang } \\
\text { batas }\end{array}$ & $\begin{array}{l}\text { 1. Host dan } \\
\text { grafik } \\
\text { terdaftar } \\
\text { dalam thold } \\
\text { 2. Host dan } \\
\text { grafil } \\
\text { memiliki } \\
\text { nilai } \\
\text { ambang } \\
\text { batas }\end{array}$ & \begin{tabular}{|l|} 
Host dan \\
grafik \\
terdaftar \\
dalam \\
thold serta \\
memiliki \\
nilai \\
ambang \\
batas
\end{tabular} & \begin{tabular}{|l} 
Host dan \\
grafik \\
tercaftar \\
dalam \\
thold serta \\
memiliki \\
nilai \\
ambang \\
batas
\end{tabular} \\
\hline
\end{tabular}

Hasil pengujian pendaftaran host pada thold dapat dilihat pada gambar 3.30.

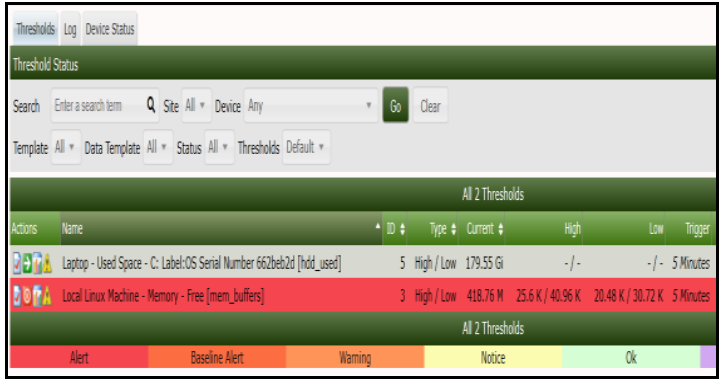

Gambar 3.30 Hasil pengujian pendaftaran

Host pada Thold

\subsubsection{Pengujian Email Alert}

Pengujian berupa hasil email yang telah dikirimkan oleh Server Cacti kepada admin yang telah dikonfigurasi sebelumnya. Pada tabel 3.5 merupakan pengujian untuk email alert pada Cacti.

\subsection{Tabel pengujian email alert}

\begin{tabular}{|c|c|c|c|c|c|}
\hline Deskripsi & $\begin{array}{l}\text { Prosedur } \\
\text { Pengujian }\end{array}$ & Masukan & \begin{tabular}{|l} 
Keluaran \\
yang \\
Diharapkan
\end{tabular} & \begin{tabular}{|l} 
Kriteria \\
Eraluasi \\
Hasil
\end{tabular} & $\begin{array}{l}\text { Hasil yang } \\
\text { Didapat }\end{array}$ \\
\hline \begin{tabular}{|l|} 
Pengujalan \\
Pengiriman \\
Email
\end{tabular} & $\begin{array}{l}\text { 1. Klik thold. } \\
\text { 1. Ces Notification } \\
\text { List dan Email } \\
\text { Address. } \\
\text { 2. Cek pada Email } \\
\text { Penerima apakan } \\
\text { Email sudah } \\
\text { diterima. }\end{array}$ & $\begin{array}{l}\text { 1. Pilihan } \\
\text { Host } \\
\text { 2. Pilihan } \\
\text { Grafili } \\
\text { 3. Email } \\
\text { Address } \\
\text { Penerima }\end{array}$ & $\begin{array}{l}\text { Email peringatan } \\
\text { sesuai thald } \\
\text { berserta } \\
\text { grafiknya dan } \\
\text { diterima pada } \\
\text { Email penerima. }\end{array}$ & \begin{tabular}{|l|} 
Email \\
peringatan \\
sesuai thold \\
berserta \\
grafilinya \\
dan \\
diterima \\
pada \\
Email \\
penerima.
\end{tabular} & \begin{tabular}{|l|} 
Email \\
masalah \\
dikiriim \\
beserta \\
grafik dan \\
informasi \\
perangkat
\end{tabular} \\
\hline
\end{tabular}

Berikut hasil dari email notifikasi yang dikirim oleh sever Cacti. Email berisi sebuah permasalahan dimana kapasitas penggunaan storage pada salah satu partisi di dalam server telah melebihi ambang batas di Host dengan alamat IP Address 192.168.43.50 gambar 3.31 menunjukkan email yang telah dikirim 
Server Cacti.

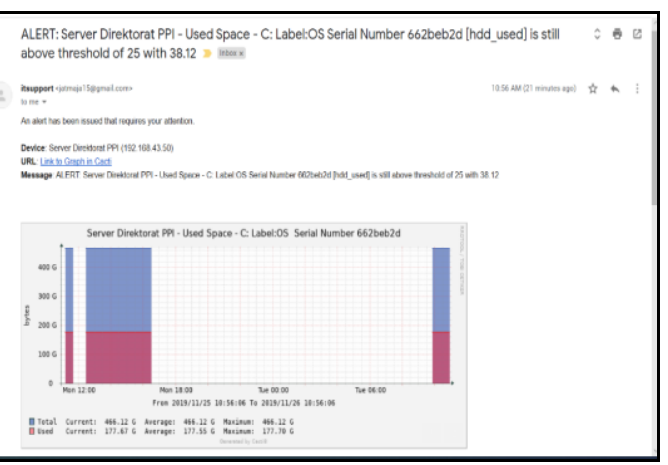

Gambar 3.31 Hasil pengujian email alert

\subsubsection{Pengujian Management Disk}

\section{Client}

Tujuan dari pengujian ini adalah untuk dapat melihat besaran daridisk yang sedang digunakan oleh server yang nantinya dapat memperingatkan admin bahwa perlu perlu dilakukan penambahankapasitas atau pembersihan file tidak penting jika hard disk sudah penuh. Hasil pengujian dapat dilihat pada gambar 3.32.

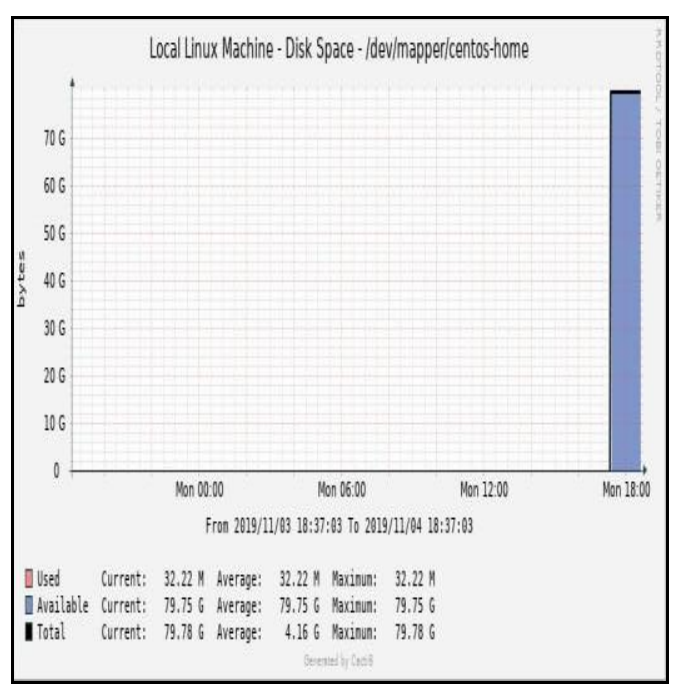

Gambar 3.32 Hasil pengujian management disk client

\subsubsection{Pengujian Memory Client}

Tujuan dari pengujian ini adalah untuk dapat dapat melihat besaran dari memory yang sedang digunakan oleh server yang nantinya dapat memperingatkan admin bahwa perlu perlu dilakukan penambahan kapasitas jika memory dirasa tidak cukup. Hasil pengujian dapat dilihat pada gambar 3.33 .

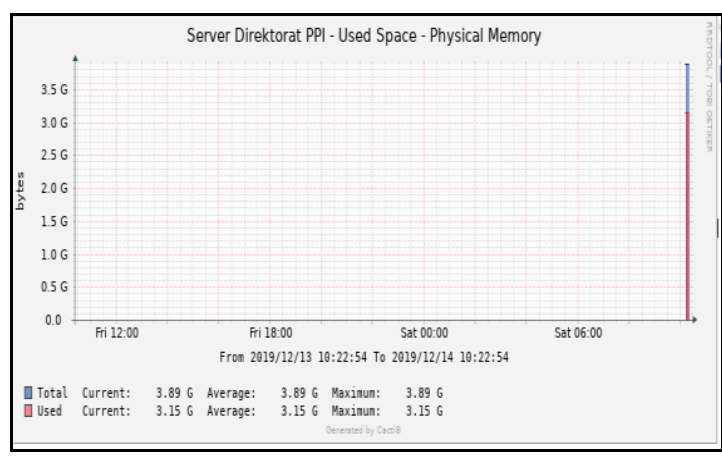

Gambar 3.33 Hasil pengujian memory client

\subsection{Identifikasi Kendala Yang Dihadapi}

Pengalaman yang didapatkan selama PKL adalah tentang bisnis apa saja yang dapat dijalankan dalam pemanfaatan teknologi informasi. Keterampilan yang didapatkan selama PKL adalah dapat menginstalasi dan konfigurasi Cent OS dan Network Monitoring System di Server.

\subsubsection{Kendala Pelaksanaan Tugas}

Kendala dalam melaksanakan tugas selama PKL sebagai berikut: 
- Belum pernah menggunakan CentOS sebelumnya dan command CentOS berbeda dengan Linux.

- CentOS 6 yang digunakan tidak akan disupport oleh CentOS.

- Crontab CentOS tidak berjalan sehingga grafik Cacti tidak muncul

- Plugin Thold tidak mendukung versi Cacti dibawah 1.0

- Send Mail Cacti tidak dapat langsung digunakan.

- Gagal dalam mengirim alert ke email admin.

\subsubsection{Cara Mengatasi Kendala}

Berikut cara mengatasi masalah selama melaksanakan tugas PKL:

- Karena CentOS 6 tidak akan disupport lagi dengan CentOS. Melakukan migrasi ke CentOS 7 dengan persetujuan pembimbing industri.

- Memperlajari beberapa command penting di CentOS melalui Google.

- Menginstall rpm realease yang terbaru agar crontab Cacti dapat berjalan. 


\section{PENUTUP}

\subsection{Kesimpulan}

Praktek Kerja Lapangan telah dilakukan membahas tentang instalasi dan konfigurasi Network Monitoring System yang meliputi perancangan, implementasi dan pengujian, sehingga diperoleh beberapa kesimpulan di antaranya sebagai berikut:

1. Monitoring berhasil dilakukan untuk melihat kondisi UP atau Down dari sebuah Host.

2. Sistem monitoring berhasil mendeteksi perubahan status Host yang terjadi.

3. Hasil monitoring berhasil diakses menggunakan web browser dengan memasukkan ip Server.

4. Hasil monitoring juga berhasil memberi gambaran tren yang sedang terjadi terhadap Host.

5. Sistem monitoring berhasil menggunakan Email alert untuk mempermudah admin agar mendapatkan informasi kondisi Host dimana saja.

\subsection{Saran}

Adapun saran adalah sebagai berikut:

1. Sebaiknya dikembangakan lagi untuk adanya fitur alert melalui whatsapp atau sms untuk mempermudah admin dalam melihat kondisi Host.

2. Sebaiknya disiapkan satu staff khusus yang bertanggung jawab dalam memegang Cacti di bulan April karena di waktu tersebut Server banyak di akses oleh penyelenggara jasa telekomunikasi untuk mengupload Laporan Kerja Operasional (LKO).

3. Jika sever pelaporan tahunan tidak dapat di akses pada saat peak-time yaitu di bulan April sebaiknya melakukan penambahan RAM dan Hardisk atau mengganti Server dengan spesifikasi yang lebih tinggi. 


\section{DAFTAR PUSTAKA}

Blog Dimensi Data. 2019. "Komputer Server"

(https://blog.dimensidata.com/ko

mputer-client-dan-Server-

pengertian-perbedaan-fungsinya/).

[29 November 2019].

Cacti Home Page. 2019. "Software Cacti”

(http://www.Cacti.net/index.php).

[29 November 2019].

Cacti Docs. 2019. "Plugin Thold" (https://docs.Cacti.net/plugin:thold ) [29 November 2019].

Fatahna, M. A. 2011. E-Book CentOS Network Administrator. 106. [29 November 2019].
Hidayat, W. N. 2010. Membangun Mail

Server Berbasis Linux

Menggunakan Postfix. [29

November 2019].

Mauro, D., dan Schmidt, K. 2009. Essential SNMP, 2nd Edition. O'Reilly Media, 464. [29 November 2019].

Raharja, Budi, Risza, Dwi, Peryadi, S. A. 2015. Implemetasi Monitoring Jaringan Menggunakan Cacti Dan Web Authentication Menggunakan Kerberos Pada Man 1 Bojonegor. E-Proceeding of Applied Science, 1(3), 2323-2333. [29 November 2019].

Syamsudin. 2014. 60 Menit Belajar Monitoring Jaringan (Cacti). 5(1), 172. [29 November 2019]. 
